\title{
Soy isoflavones increase preprandial peptide YY (PYY), but have no effect on ghrelin and body weight in healthy postmenopausal women
}

\author{
Martin O Weickert* ${ }^{* 1,2}$, Manja Reimann ${ }^{\dagger 1,3}$, Bärbel Otto ${ }^{4}$, Wendy L Hall5, \\ Katherina Vafeiadou ${ }^{5}$, Jesper Hallund ${ }^{6}$, Marika Ferrari ${ }^{7}$, Duncan Talbot ${ }^{8}$, \\ Francesco Branca ${ }^{7}$, Susanne Bügel ${ }^{6}$, Christine M Williams ${ }^{5}$, Hans- \\ Joachim Zunft ${ }^{1}$ and Corinna Koebnick ${ }^{1,9}$
}

Address: ${ }^{1}$ German Institute of Human Nutrition Potsdam-Rehbruecke, Nuthetal, Germany, ${ }^{2}$ Dept. of Endocrinology, Diabetes and Nutrition, Charité-University-Medicine, Berlin, Germany, ${ }^{3}$ School for Physiology, Nutrition and Consumer Sciences, North-West University PotchefstroomCampus, Potchefstroom, South Africa, ${ }^{4}$ Medical Dept., University Hospital Innenstadt, Munich, Germany, ${ }^{5}$ School of Food Biosciences, University of Reading, Reading, UK, ${ }^{6}$ The Royal Veterinary \& Agricultural University, Research Dept. of Human Nutrition, Centre for Advanced Food Studies, Frederiksberg, Denmark, 7 Istituto Nazionale di Ricerca per gli Alimenti e la Nutrizione, Rome, Italy, ${ }^{8}$ Unilever Corporate Research, Colworth House, Sharnbrook, Bedfordshire, UK and ${ }^{9}$ Dept. of Preventive Medicine, University of Southern California, Los Angeles, USA

Email: Martin O Weickert* - m.weickert@dife.de; Manja Reimann - FLGMR@puknet.puk.ac.za; Bärbel Otto - Baerbel.Otto@med.unimuenchen.de; Wendy L Hall - wendy.hall@kcl.ac.uk; Katherina Vafeiadou - a.vafeiadou@reading.ac.uk; Jesper Hallund - jeha@kvl.dk; Marika Ferrari - Ferrari@inran.it; Duncan Talbot - Duncan.Talbot@unilever.com; Francesco Branca - f.branca@inran.it; Susanne Bügel - shb@kvl.dk; Christine M Williams - c.m.williams@reading.ac.uk; Hans-Joachim Zunft - zunft@dife.de; Corinna Koebnick - koebnick@usc.edu

* Corresponding author †Equal contributors

Published: 14 August 2006

Journal of Negative Results in BioMedicine 2006, 5: I I doi:10.1 I86/1477-575 I-5-I I
Received: 02 June 2006

Accepted: 14 August 2006

This article is available from: http://www.jnrbm.com/content/5/I/I I

(c) 2006 Weickert et al; licensee BioMed Central Ltd.

This is an Open Access article distributed under the terms of the Creative Commons Attribution License (http://creativecommons.org/licenses/by/2.0), which permits unrestricted use, distribution, and reproduction in any medium, provided the original work is properly cited.

\begin{abstract}
Background: Soy isoflavones show structural and functional similarities to estradiol. Available data indicate that estradiol and estradiol-like components may interact with gut "satiety hormones" such as peptide YY (PYY) and ghrelin, and thus influence body weight. In a randomized, double-blind, placebo-controlled, cross-over trial with 34 healthy postmenopausal women (59 \pm 6 years, BMI: $\left.24.7 \pm 2.8 \mathrm{~kg} / \mathrm{m}^{2}\right)$, isoflavone-enriched cereal bars (50 mg isoflavones/day; genistein to daidzein ratio 2:I) or nonisoflavone-enriched control bars were consumed for 8 weeks (wash-out period: 8-weeks). Seventeen of the subjects were classified as equol producers. Plasma concentrations of ghrelin and PYY, as well as energy intake and body weight were measured at baseline and after four and eight weeks of each intervention arm.

Results: Body weight increased in both treatment periods (isoflavone: $0.40 \pm 0.94 \mathrm{~kg}, \mathrm{P}<0.00 \mathrm{I}$; placebo: $0.66 \pm 0.87 \mathrm{~kg}, \mathrm{P}=$ $0.018)$, with no significant difference between treatments. No significant differences in energy intake were observed $(P=0.634)$. PYY significantly increased during isoflavone treatment $(5 \mathrm{I} \pm 2 \mathrm{pmol} / \mathrm{L}$ vs. $55 \pm 2 \mathrm{pmol} / \mathrm{L})$, but not during placebo $(52 \pm 3 \mathrm{pmol} /$ $L$ vs. $50 \pm 2 \mathrm{pmol} / \mathrm{L}),(P=0.010$ for treatment differences, independent of equol production). Baseline plasma ghrelin was significantly lower in equol producers $(110 \pm 16 \mathrm{pmol} / \mathrm{L})$ than in equol non-producers $(162 \pm 17 \mathrm{pmol} / \mathrm{L} ; \mathrm{P}=0.025)$.

Conclusion: Soy isoflavone supplementation for eight weeks did not significantly reduce energy intake or body weight, even though plasma PYY increased during isoflavone treatment. Ghrelin remained unaffected by isoflavone treatment. A larger and more rigorous appetite experiment might detect smaller differences in energy intake after isoflavone consumption. However, the results of the present study do not indicate that increased PYY has a major role in the regulation of body weight, at least in healthy postmenopausal women.
\end{abstract}




\section{Background}

Several intervention studies in humans and animals suggest that consumption of soy and isoflavone-rich soy protein may decrease body weight $[1,2]$. Postmenopausal women with relatively high isoflavone consumption in their normal diet showed an inverse association with obesity in a cross-sectional study [3]. However, the protein content of soy may be at least partly responsible for the observed effects, and the contribution of soy isoflavones such as genistein and daidzein remains uncertain $[4,5]$. There is some evidence that may link isolated isoflavone consumption per se to the regulation of body weight. Soy isoflavones show functional and structural similarities to estradiol [6], mainly by binding to the estrogen receptor $\beta$ [7]. In ovariectomized mice, loss of circulating estrogen increases body weight and fat mass, and this is reversed by estrogen replacement $[8,9]$. Similar effects have been observed in ovariectomized mice treated with oral genistein $[10,11]$. Even though the role of postmenopausal hormone replacement in modulating body weight is controversial $[12,13]$, some studies indicate that the activation of the estrogen receptor interferes with the regulation of gut hormones commonly thought to be involved in the regulation of food intake. Food intake decreases during the high estrogen period in the estrous cycle in rats, and estradiol replacement in ovariectomized rats increased the satiating effect of the gut hormone cholecystokinin [14]. Estrogen replacement in hysterectomized postmenopausal women also increased peripheral concentrations of the orexigenic gut hormone ghrelin [15]. Peptide YY (PYY), a member of the neuropeptide Y (NPY) family and another gut derived "satiety hormone", is assumed to have potent anorexigenic properties, with potential therapeutic use in obese humans [16]. Human PYY has been shown to be regulated in a gender specific manner, with higher PYY secretion in females than in males [17]. Treatment of ovariectomized rodents with estradiol increases the number of receptors of several neuropeptides, including NPY receptors in the brain [18]. To date, potential effects of isolated isoflavones on PYY have not been reported, and only one study investigated effects of isolated isoflavones on total ghrelin concentrations [19]. In addition, no long-term randomized controlled studies have investigated whether changes in PYY concentrations influence food intake in free living humans. The hypothesis of the present study was that estradiol-like properties of isolated isoflavones may influence PYY and ghrelin, and thus energy intake and body weight.

\section{Results}

Results of biomarkers are given as postabsorptive concentrations, measured after a standardized low-fat evening meal and after $12 \mathrm{~h}$ overnight fasts. P values for PYY, glucose, insulin and ghrelin are given for the treatment effect within a linear mixed model. Differences from baseline were used as response variable after adjustment for changes in BMI.

\section{Dietary intake and body weight}

Dietary intake was assessed at baseline and after four weeks of each intervention arm. Macronutrient intake at baseline was $15 \%$ of energy as protein, $34 \%$ as fat, and $47 \%$ as carbohydrate. Even though participants were instructed to replace snacks by the cereal bars, body weight increased moderately, but significantly, during both intervention periods (placebo $+0.66 \pm 0.87 \mathrm{~kg}$, $(\mathrm{P}=$ $0.018)$; isoflavones $+0.40 \pm 0.94 \mathrm{~kg},(P<0.001))$. There was no significant difference in body weight and body mass index $(\mathrm{P}>0.331)$ between treatments (table 1). There were no significant differences in energy intake or macronutrient intake, both across the treatments and compared to baseline (wk4 - wk0; interaction treatment vs. time, $\mathrm{P}=0.634$ ).

\section{Effect of isoflavone consumption on PYY}

During isoflavone consumption, PYY concentrations increased by eight percent, and during placebo consumption, PYY concentrations decreased by four percent $(\mathrm{P}=$ 0.010 for treatment differences) (table 1 ).

Changes in PYY levels were independent of changes in BMI, and were negatively correlated with baseline PYY ( $r$

Table I: Plasma PYY, body weight, and urinary isoflavone concentrations in postmenopausal women, at baseline (t0) and after 8 weeks $(t 8)$ of isoflavone or placebo consumption $(n=34)$

\begin{tabular}{llllll}
\hline & $\begin{array}{l}\text { Isoflavones } \\
\text { t0 }\end{array}$ & t8 & $\begin{array}{l}\text { Placebo } \\
\text { t0 }\end{array}$ & t8 & P valuel \\
\hline Total PYY (pmol/L) & $51 \pm 2$ & $55 \pm 2$ & $52 \pm 3$ & $50 \pm 2$ & 0.010 \\
BMI (kg/m²) & $24.5 \pm 2.7$ & $24.6 \pm 2.7$ & $24.5 \pm 2.8$ & $24.7 \pm 2.8$ & 0.331 \\
Glucose (mmol/L) & $5.7 \pm 0.1$ & $5.6 \pm 0.1$ & $5.7 \pm 0.1$ & $5.6 \pm 0.1$ & 0.641 \\
Insulin (pmol/L) & $37 \pm 3$ & $39 \pm 3$ & $38 \pm 3$ & $34 \pm 3$ & 0.231 \\
Total ghrelin (pmol/L) & $129 \pm 12$ & $131 \pm 12$ & $133 \pm 13$ & $123 \pm 11$ & 0.297 \\
\hline
\end{tabular}

Data are given as mean \pm SEM except for $B M I$ which is presented as mean \pm SD. $B M I=$ body mass index.

$I P$ values are shown for the treatment effect within a linear mixed model. Differences from baseline were used as response variable after adjustment for changes in BMI. 
$=-0.67 ; \mathrm{P}<0.001)$. PYY concentrations were not significantly different between equol producers and equol nonproducers.

\section{Effect of isoflavone consumption on ghrelin}

At baseline, ghrelin was significantly lower in equol producers $(110 \pm 16 \mathrm{pmol} / \mathrm{L})$ than in equol non-producers $(162 \pm 17 \mathrm{pmol} / \mathrm{L}) ;(\mathrm{P}=0.025)$, independent of BMI. However, isoflavone treatment did not affect ghrelin concentrations (table 1).

\section{Other parameters}

During isoflavone treatment, urinary genistein and daidzein excretion increased 15 fold and 24 fold, respectively. There was no significant increase in urinary genistein and daidzein concentrations following placebo treatment. According to the cut-offs used in the present study [20], 50 percent of the participants $(n=17)$ were classified as equol producers. Equol production increased 35 fold in equol producers during the active treatment, compared to an 1.7 fold increase in equol non-producers (table 2).

Plasma glucose and insulin were unaffected by isoflavone treatment (table 1).

\section{Power analysis}

A between-treatment difference in body weight $>500 \mathrm{~g}$ after 8 weeks intervention was assumed to be relevant. The estimated power of this study was 94 percent to detect a difference of $500 \pm 900 \mathrm{~g}$ in body weight between treatments with a sample size of 34 subjects and a significance level of 0.05 .

\section{Discussion}

Consumption of soy derived food rich in isoflavones has been suggested to have favorable effects on energy intake and body weight [5]. However, soy derived food is also rich in protein, and an increased protein intake might be responsible for the observed effects. The potential contribution of isolated isoflavones to the regulation of energy and body weight remains uncertain. In the present study, isoflavone treatment for eight weeks did not significantly influence energy intake, macronutrient intake, or body weight, both across the treatments or compared to baseline. Isoflavone treatment did not affect preprandial ghrelin, which seems to be in contrast to results of a previous study that investigated effects of isoflavone treatment on ghrelin concentrations [19]. However, the observed differences in the mentioned study are mainly due to increased ghrelin concentrations in the placebo group rather than altered ghrelin concentrations after isoflavone intake. In addition, high within and between subject variations in preprandial ghrelin concentrations have been reported, which may lead to the detection of random effects rather than of true treatment effects [21]. Despite unchanged ghrelin concentrations during isoflavone treatment in the present study, the ability of producing equol, a gut bacterial metabolite of daidzein with higher binding affinity to estrogen receptors compared with its precursor [22], was associated with lower ghrelin concentrations at baseline. The capability to produce equol is greatly varying between individuals, with about $30-40 \%$ equol producers in the Western population [22]. It is speculated that equol producers may have an increased benefit from soy consumption [20,23]. However, even though the ability of producing equol was associated with lower ghrelin concentrations at baseline, ghrelin responses remained unaffected during isoflavone treatment in the present study. This indicates that equol may have a long-term suppressive effect on ghrelin concentrations, which probably will not respond to further and relatively short-term increases of equol concentrations. In contrast to unchanged ghrelin in the present study, isolated soy isoflavones significantly increased plasma PYY concentrations. Given the assumed potent anorexigenic properties of PYY [16], our data do not suggest a major role of PYY on the regulation of body weight. Notably, power analysis indicated that even a moderate difference in body weight between treatments was highly likely to be detected. Only moderate effects of PYY on the regulation of body weight may contribute to the explanation of controversial findings in the literature. In humans, short-term intravenous administration of PYY

Table 2: Urinary isoflavone concentrations in postmenopausal women at baseline (t0) and week 8 (t8) of isoflavone and placebo arms $(n=34)$

\begin{tabular}{|c|c|c|c|c|c|}
\hline & \multicolumn{2}{|l|}{ Isoflavones } & \multicolumn{2}{|l|}{ Placebo } & \multirow[t]{2}{*}{$P$ value ${ }^{\prime}$} \\
\hline & to & t8 & to & t8 & \\
\hline Genistein (nmol/L) & $808 \pm 134$ & $12266 \pm 852$ & $655 \pm 68$ & $647 \pm 73$ & $<0.001$ \\
\hline Daidzein (nmol/L) & $334 \pm 88$ & $8146 \pm 651$ & $315 \pm 82$ & $223 \pm 40$ & $<0.001$ \\
\hline Equol, (nmol/L) & $154 \pm 12$ & $3040 \pm 713$ & $162 \pm 15$ & $198 \pm 23$ & $<0.001$ \\
\hline $\begin{array}{l}\text { Equol producers (n } \\
=17)\end{array}$ & $164 \pm 11$ & $5834 \pm 749$ & $179 \pm 16$ & $237 \pm 29$ & $<0.001$ \\
\hline $\begin{array}{l}\text { Equol non- } \\
\text { producers }(n=17)\end{array}$ & $143 \pm 14$ & $245 \pm 16$ & $145 \pm 13$ & $160 \pm 12$ & $<0.001$ \\
\hline
\end{tabular}

Data are given as mean \pm SEM.

I $P$ values are shown for the treatment effect within a linear mixed model. Differences from baseline were used as response variable. 
[3-36] in supraphysiological $[24,25]$, but not in physiological doses [25] reduces appetite and food intake. Longterm studies in humans are not available to date. A two weeks continous PYY infusion in colectomized rats did not affect food intake and body weight [26], and data obtained from other animal studies are controversially discussed [27]. The duration of the present study may have been too short to detect relevant differences in body weight. However, most studies linking physiological ghrelin and PYY responses to food intake investigated the effects of only one meal. A relatively small but well performed study over 16 weeks did not show an effect of macronutrient intake and energy intake on preprandial ghrelin [21]. It needs, however, to be emphasized that food diaries, and not weighed food intake were used to assess energy intake in the present study, and a more rigorous appetite experiment might detect smaller effects. In addition, adaptation processes and counter regulatory responses in other satiety hormones than total ghrelin, such as acylated ghrelin, glucagon-like peptide (GLP-1), or cholecystokinin may have masked detectable differences in energy intake or body weight.

\section{Conclusion}

Isoflavone treatment had no effect on energy intake and body weight, despite significantly increased preprandial PYY concentrations. The findings indicate that PYY is not a major factor in the regulation of body weight. Preprandial ghrelin was not affected by isoflavone consumption. The isoflavone contents are not likely to explain the observed beneficial effects of soy consumption on energy intake and body weight.

\section{Methods \\ Subjects}

This study was part of a multi-center intervention located in Frederiksberg (Denmark), Reading (UK), Rome (Italy), and Potsdam (Germany). Potential effects of isoflavones on gut satiety hormones and body weight were investigated in the German population. Thirty-six healthy postmenopausal women (age $59 \pm 6$ y, BMI $24.7 \pm 2.8 \mathrm{~kg} / \mathrm{m}^{2}$ ), defined as at least 12 months since the last menstrual cycle, were recruited by advertisement in the local media. Thirty-four of the subjects completed the intervention. One of the subjects was excluded because of a prolonged respiratory infection, the other one because of start of a treatment with an angiotensin-converting-enzyme inhibitor. None of the volunteers had used hormone replacement therapy for six months, antibiotics for three months, or isoflavone, vitamin, or mineral containing supplements for two months. All volunteers were non-smokers. Parameters of renal and liver function were within normal range. Subjects were classified as equol producers, when equol in a $24 \mathrm{~h}$ urine sample exceeded $936 \mathrm{nmol} /$ liter during isoflavone treatment, which corresponds to an urinary equol excretion of $>0.45 \mathrm{mg} /$ day [20]. The study protocol was approved by the Ethics Committee of the University of Potsdam, Germany. All volunteers gave written informed consent prior to the study.

\section{Study design}

This was a randomized, double-blind, placebo-controlled, $2 \times 8$-wk crossover study, separated by an 8 -wk washout period. Subjects were invited to the metabolic unit on 6 occasions ( $\mathrm{t} 0$, $\mathrm{t} 4$, and $\mathrm{t} 8$ on each intervention arm), after 12-h overnight fasts. To exclude potential second-meal effects, a set low-fat evening meal ( $<10 \mathrm{~g}$ fat) was consumed the evening before each of the study days. Recipes for the preparation of the meals were provided to the participants. Energy contents of the meals were comparable. Subjects were asked to consume two fruit cereal bars/d (Health \& Diet Food, Manchester, UK), one in the morning and one in the afternoon, in addition to their normal diet. During the treatment period, cereal bars were enriched with $2 \times 25 \mathrm{mg}$ isoflavones/d, with a genistein to daidzein ratio of 2:1 ("Solgen 40", Solbar Plant Extracts, Ashdod, Israel). Thus, isoflavone intake in the treatment group of the present study was in the upper range of the daily isoflavone intake in traditional Asian diets (15 - 50 $\mathrm{mg} / \mathrm{d})[28]$. The product was tested before packaging and during the study by HPLC, to ensure stability of the isoflavones [29]. Placebo did not contain any isoflavones. Each cereal bar ( $40 \mathrm{~g})$ had an average nutrient content of energy $(652 \mathrm{~kJ})$; protein $2.6 \mathrm{~g}$; carbohydrate $17.3 \mathrm{~g}$; fat $8.5 \mathrm{~g}$; fiber $1.8 \mathrm{~g}$; sodium $0.012 \mathrm{~g}$. Subjects perceived the isoflavoneenriched and placebo cereal bars as identical in taste and visual appearance. Habitual diet was assessed by estimated 3-d food records three times during the study. Diet diaries were completed at baseline ( $\mathrm{t} 0$ ) and after 4 weeks (t4) of each intervention arm. All food records included two week days and one weekend day. Nutrient intake was calculated based on the German Food and Nutrient Data Base Bundeslebensmittelschlüssel BLS II.3 [30]. To avoid weight gain, subjects were advised to replace snacks with the cereal bars. Subjects kept daily records of cereal bar consumption and well-being in a study diary. Dietary compliance was further assessed by measurement of phytoestrogen concentrations in 24-hour urine [31], which was collected at start and end of each intervention period. Body weight was measured at each visit.

\section{Biochemical parameters}

Blood was collected in ice-chilled EDTA tubes for the analysis of glucose, ghrelin, and PYY. Following centrifugation at $1600 \mathrm{~g}$ for 10 minutes at $4^{\circ} \mathrm{C}$, aliquots were immediately frozen at $-20^{\circ} \mathrm{C}$ until assayed. All samples from individual subjects were measured in the same assay. Immunoreactive total ghrelin was measured by a commercially available radioimmunoassay (Phoenix Pharmaceuticals, Mountain View, CA, USA), as previously 
described [32]. Immunoreactive total human PYY was measured by a commercially available radioimmunoassay (LINCO Research, Missouri, USA), using ${ }^{125}$ I-labeled bioactive PYY as tracer and a PYY antiserum to determine the level of active PYY by the double antibody/PEG technique. The PYY antibody is raised in guinea pigs and recognizes both the PYY 1-36 and PYY 3-36 forms of human PYY. Intra- and inter-assay coefficient of variation was $5.3 \%$ and $7.0 \%$, respectively. Insulin, and glucose, and urinary phytoestrogens (genistein, daidzein, equol) were analyzed as previously described [33].

\section{Statistical analyses}

Data are given as mean \pm SEM, anthropometric data are given as mean $\pm \mathrm{SD}$. Changes from baseline, e.g. week-8 compared to week-0 ( $\mathrm{t} 8$ - $\mathrm{t} 0$ ), were used as the dependent variables. Data were calculated as changes from baseline on the original scale, when normally distributed. Skewed data where log transformed, and changes from baseline on the log scale were calculated, and these changes now correspond to a multiplicative change from baseline on the original scale. Subjects were included as a random factor within a linear mixed model. Fixed effects included in the final model were: baseline parameters, treatment, treatment order, and changes in BMI. Further exploratory investigation of equol group was included in the model. Pearson's correlation coefficient was calculated between baseline PYY and changes in PYY. Statistical analysis was performed using SAS 8.4 (SAS Institute Inc., Cary, NC).

\section{Abbreviations}

BMI: body mass index; PYY: peptide YY.

\section{Competing interests}

This study was carried out with financial support from the Commission of the European Communities, ISOHEART QLK1-2001-00221. It does not necessarily reflect its views and in no way anticipates the Commission's future policy in this area. The authors declare that they have no competing interests.

\section{Authors' contributions}

$\mathrm{MOW}, \mathrm{BO}, \mathrm{CK}$, and $\mathrm{MR}$ were responsible for data analysis and writing of the manuscript. S B, CMW, and HJZ were responsible for the study design and were involved in all aspects of the study as well as manuscript review. MR, JH and $\mathrm{MF}$, and $\mathrm{KV}$ were involved in the collection of the data. BO, WLH, and DT were responsible for laboratory analysis. All authors contributed to the manuscript.

\section{References}

I. Bosello O, Cominacini L, Zocca I, Garbin U, Compri R, Davoli A, Brunetti L: Short- and long-term effects of hypocaloric diets containing proteins of different sources on plasma lipids and apoproteins of obese subjects. Ann Nutr Metab 1988, 32:206-2I4.
2. Aoyama T, Fukui K, Takamatsu K, Hashimoto $Y$, Yamamoto T: Soy protein isolate and its hydrolysate reduce body fat of dietary obese rats and genetically obese mice (yellow KK). Nutrition 2000, 16:349-354.

3. Goodman-Gruen D, Kritz-Silverstein D: Usual dietary isoflavone intake is associated with cardiovascular disease risk factors in postmenopausal women. J Nutr 200I, I3 I:I202-I206.

4. Halton TL, Hu FB: The effects of high protein diets on thermogenesis, satiety and weight loss: a critical review. J Am Coll Nutr 2004, 23:373-385.

5. Bhathena SJ, Velasquez MT: Beneficial role of dietary phytoestrogens in obesity and diabetes. Am J Clin Nutr 2002, 76:II9I-I20I.

6. Knight DC, Eden JA: A review of the clinical effects of phytoestrogens. Obstet Gynecol 1996, 87:897-904.

7. Kuiper GG, Lemmen JG, Carlsson B, Corton JC, Safe SH, van der Saag PT, van der Burg B, Gustafsson JA: Interaction of estrogenic chemicals and phytoestrogens with estrogen receptor beta. Endocrinology 1998, 139:4252-4263.

8. McElroy JF, Wade GN: Short- and long-term effects of ovariectomy on food intake, body weight, carcass composition, and brown adipose tissue in rats. Physiol Behav 1987, 39:36I-365.

9. Mohamed MK, Abdel-Rahman AA: Effect of long-term ovariectomy and estrogen replacement on the expression of estrogen receptor gene in female rats. Eur J Endocrinol 2000, |42:307-3|4.

10. Naaz A, Yellayi S, Zakroczymski MA, Bunick D, Doerge DR, Lubahn $D B$, Helferich WG, Cooke PS: The soy isoflavone genistein decreases adipose deposition in mice. Endocrinology 2003, 144:3315-3320.

11. Kim HK, Nelson-Dooley C, Della-Fera MA, Yang JY, Zhang W, Duan J, Hartzell DL, Hamrick MW, Baile CA: Genistein decreases food intake, body weight, and fat pad weight and causes adipose tissue apoptosis in ovariectomized female mice. J Nutr 2006, 136:409-4|4

12. Kristensen K, Pedersen SB, Vestergaard P, Mosekilde L, Richelsen B: Hormone replacement therapy affects body composition and leptin differently in obese and non-obese postmenopausal women. J Endocrinol 1999, 163:55-62.

13. Augoulea A, Mastorakos G, Lambrinoudaki I, Christodoulakos G, Creatsas G: Role of postmenopausal hormone replacement therapy on body fat gain and leptin levels. Gynecol Endocrinol 2005, 20:227-235.

14. Geary N, Trace D, McEwen B, Smith GP: Cyclic estradiol replacement increases the satiety effect of CCK-8 in ovariectomized rats. Physiol Behav 1994, 56:28I-289.

15. Kellokoski E, Poykko SM, Karjalainen AH, Ukkola O, Heikkinen J, Kesaniemi YA, Horkko S: Estrogen replacement therapy increases plasma ghrelin levels. J Clin Endocrinol Metab 2005, 90:2954-2963.

16. Small CJ, Bloom SR: The therapeutic potential of gut hormone peptide YY3-36 in the treatment of obesity. Expert Opin Investig Drugs 2005, 14:647-653.

17. Kim BJ, Carlson OD, Jang HJ, Elahi D, Berry C, Egan JM: Peptide YY is secreted after oral glucose administration in a gender-specific manner. J Clin Endocrinol Metab 2005, 90:6665-667I.

18. Parker SL, Carroll BL, Kalra SP, St-Pierre S, Fournier A, Crowley WR: Neuropeptide $Y \mathbf{Y} 2$ receptors in hypothalamic neuroendocrine areas are up-regulated by estradiol and decreased by progesterone cotreatment in the ovariectomized rat. Endocrinology 1996, 137:2896-2900.

19. Nikander E, Tiitinen A, Laitinen K, Tikkanen M, Ylikorkala O: Effects of isolated isoflavonoids on lipids, lipoproteins, insulin sensitivity, and ghrelin in postmenopausal women. J Clin Endocrinol Metab 2004, 89:3567-3572.

20. Setchell KD, Brown NM, Lydeking-Olsen E: The clinical importance of the metabolite equol-a clue to the effectiveness of soy and its isoflavones. J Nutr 2002, 132:3577-3584.

21. Paul DR, Kramer M, Rhodes DG, Rumpler WV: Preprandial ghrelin is not affected by macronutrient intake, energy intake or energy expenditure. J Negat Results Biomed 2005, 4:2.

22. Manach C, Williamson G, Morand C, Scalbert A, Remesy C: Bioavailability and bioefficacy of polyphenols in humans. I. Review of 97 bioavailability studies. Am J Clin Nutr 2005, 8I:230S-242S. 
23. Duncan AM, Merz-Demlow BE, Xu X, Phipps WR, Kurzer MS: Premenopausal equol excretors show plasma hormone profiles associated with lowered risk of breast cancer. Cancer Epidemiol Biomarkers Prev 2000, 9:58I-586.

24. Batterham RL, Cohen MA, Ellis SM, Le Roux CW, Withers DJ, Frost GS, Ghatei MA, Bloom SR: Inhibition of food intake in obese subjects by peptide YY3-36. N Engl J Med 2003, 349:94I-948.

25. Degen L, Oesch S, Casanova M, Graf S, Ketterer S, Drewe J, Beglinger C: Effect of peptide YY3-36 on food intake in humans. Gastroenterology 2005, 1 29: | 430-1436.

26. Babu M, Purhonen AK, Bansiewicz T, Makela K, Walkowiak J, Miettinen P, Herzig KH: Effect of total colectomy and PYY infusion on food intake and body weight in rats. Regul Pept 2005, 1 31:29-33.

27. Tschop M, Castaneda TR, Joost HG, Thone-Reineke C, Ortmann S, Klaus S, Hagan MM, Chandler PC, Oswald KD, Benoit SC, et al:: Physiology: does gut hormone PYY3-36 decrease food intake in rodents? Nature 2004, 430:. I p following 165; discussion I62 p following 165

28. de Kleijn MJ, van der Schouw YT, Wilson PW, Adlercreutz H, Mazur W, Grobbee DE, Jacques PF: Intake of dietary phytoestrogens is low in postmenopausal women in the United States: the Framingham study( I-4). J Nutr 200I, I 3 I: |826-|832.

29. de Pascual-Teresa S, Hallund J, Talbot D, Schroot J, Williams CM, Bugel S, Cassidy A: Absorption of isoflavones in humans: effects of food matrix and processing. J Nutr Biochem 2006, 17:257-264.

30. Federal Institute for Health Protection of Consumers and Veterinary Medicine: The German Food Code and Nutrient Data Base (BLS II.3): conception, structure and documentation of the data base blsdat Berlin, Germany: BgVV Publications; 1999.

31. Bingham SA: The use of 24-h urine samples and energy expenditure to validate dietary assessments. Am J Clin Nutr 1994, 59:227S-23IS.

32. Weickert MO, Mohlig M, Schofl C, Arafat AM, Otto B, Viehoff $H$, Koebnick C, Kohl A, Spranger J, Pfeiffer AF: Cereal fiber improves whole-body insulin sensitivity in overweight and obese women. Diabetes Care 2006, 29:775-780.

33. Hall WL, Vafeiadou K, Hallund J, Bugel S, Koebnick C, Reimann M, Ferrari M, Branca F, Talbot D, Dadd T, et al: Soy-isoflavoneenriched foods and inflammatory biomarkers of cardiovascular disease risk in postmenopausal women: interactions with genotype and equol production. Am J Clin Nutr 2005, 82: $1260-1268$

\section{Publish with Bio Med Central and every scientist can read your work free of charge}

"BioMed Central will be the most significant development for disseminating the results of biomedical research in our lifetime. "

Sir Paul Nurse, Cancer Research UK

Your research papers will be:

- available free of charge to the entire biomedical community

- peer reviewed and published immediately upon acceptance

- cited in PubMed and archived on PubMed Central

- yours - you keep the copyright

Submit your manuscript here:

http://www.biomedcentral.com/info/publishing_adv.asp
BiolMedcentral 